\title{
Optimization of hot-press process and structural characterization of PF Camellia oleifera cake adhesive
}

\author{
Xiao Hu ${ }^{1,3}$, Rui Zeng ${ }^{2, \S}$, Yuyuan $\mathrm{Li}^{4}$, Jinghua Zhou ${ }^{5}, \mathrm{Xi} \mathrm{Li}^{4}$, Yong Wang ${ }^{6}$, Xiang $\mathrm{Li}^{2}$, Dong Wang ${ }^{2, *}$ \\ ${ }^{1}$ Forestry College of Guangxi University, Nanning, Guangxi Province, China \\ ${ }^{2}$ Hunan Airbluer Environmental Protection Technology Co., Changsha, Hunan Province, China \\ ${ }^{3}$ Hunan Association of Environmental Improvement, Changsha, Hunan Province, China \\ ${ }^{4}$ Institute of Subtropical Agroecology, Chinese Academy of Sciences, Changsha, Hunan Province, China \\ ${ }^{5}$ Anxiang County Agricultural and Rural Bureau, Changde, Hunan Province, China \\ ${ }^{6}$ Institute of Forest Products and Industry, Hunan Academy of Forestry, Changsha, Hunan Province, China \\ $\S$ Contributed equally to this work
}

\begin{abstract}
In this paper, the result based on the techniques of indoor wood adhesive of Camellia oleifera cake and manufacturing of manmade board suggests that the most appropriate condition of preparation this adhesive is that the solid content is $50 \%$, the reaction temperature is $50{ }^{\circ} \mathrm{C}$, the reaction time is $40 \mathrm{~min}$, the dosage of $\mathrm{PF}$ resin prepolymer accounts for 50 percent. The $\mathrm{pH}$ of the reaction medium is 10 and the dosage of SDBS is $1 \%$. The proper conditions hot pressing process of PF Camellia oleifera cake adhesive for bonding plywood are the hot pressing temperature is $120^{\circ} \mathrm{C}$, and the hot pressing time is $0.7 \mathrm{~min} / \mathrm{mm}(42 \mathrm{~s} / \mathrm{mm})$, the gluing amount is $120 \mathrm{~g} / \mathrm{m}^{2}$, and the hot pressing pressure is $1.1 \mathrm{MPa}$. The average water-resistant bonding strength of the plywood prepared under this condition is $0.79 \mathrm{mpa}$, which meets the requirements of class II plate in the national standard GB / T 9846.3-2004. The emission of formaldehyde is $0.38 \mathrm{mg} / \mathrm{L}$, which meets the requirements of class E0 plate in the national standard GB 18580-2001. What's more, the cost is the lowest among all the techniques.
\end{abstract}

Key words: Camellia oleifera cake adhesive, hot pressing technique, bonding strength, manmade board.

\section{Introduction}

Board making technique is a vital step in examining the performance of adhesive. Better hot pressing technique can not only achieve a good quality of the product but also can improve manufacturing efficiency. What's more, it can reduce equipment wear and energy consumption and save cost[1]. Therefore, seeking for best hot pressing technique has already become the most important technique in applying and spreading the new wood adhesive[2]. Under the best technique, PF- Camellia oleifera cake adhesive has lots of advantages such as high bonding strength, good water resistance, less cost and E0 standard of formaldehyde emission. However, compared with commonly used urea formaldehyde resin, higher temperature is needed when pressing plywood with it.

$\left(135 \sim 140^{\circ} \mathrm{C}\right)$ this temperature is higher than that of urea formaldehyde resin for $20-30^{\circ} \mathrm{C}[3]$.this is because the composition of PF Camellia oleifera cake adhesive contains $\mathrm{PF}$ resin, protein, tannin that have reaction activity and some polymers formed by them. When these compositions need solidification, they require high activation energy[4-6].At present, there are a few studies and reports about the curing at low temperature of vegetable protein, tannin and adhesive prepared with them. However, we can find many literatures about raising curing speed and decreasing curing temperature[7-9]. Therefore, $\mathrm{Na} 2 \mathrm{CO} 3$ is used as curing agent[10]. To achieve rapid curing at low temperature, we add $\mathrm{Na} 2 \mathrm{CO} 3$ in the preparing the PF-Camellia oleifera cake adhesive. And then we study the effect of hot pressing temperature, hot pressing time, amount of glue and hot pressing pressure on the bonding performance of adhesive.

\section{Resources and methods}

\subsection{Resources}

Camellia oleifera cake protein: after drying and crushing, we make the protein pass through the $140 \sim 160$ mesh sieve. Then we use Soxhlet extraction device to add petroleum ether to remove grease and dry it out at low temperature. Take $100 \mathrm{~g}$ of degreased Camellia oleifera cake powder, then add $4000 \mathrm{ml}$ of $70 \%$ ethanol aqueous solution, adjust the $\mathrm{pH}$ of the solution to $8-11$, then perform ultrasonic extraction in a water bath at $30 \sim 60^{\circ} \mathrm{C}$,

\footnotetext{
* Corresponding author: wd195@qq.com
} 
and filter the product after a period of time to obtain the filtrate.

Then we carry out the second and third time extraction at the ratio of 100 grams residue: $4000 \mathrm{ml}$ ethanol aqueous solution. Then merge all the filtrate together and let it sit overnight. Then filter it again. Extract the supernatant at the speed of $4000 \mathrm{r} / \mathrm{min}$ for 10 minutes. Then adjust the supernatant to the Isoelectric point with $20 \% \mathrm{HCl}$. When the precipitation is stable, freeze it and dry it out. Finally, we get camellia oleifera cake protein.

PF-camellia oleifera cake adhesive: add some distilled water to the glass reaction vessel. When the temperature raises to $30-60^{\circ} \mathrm{C}$, adjust the $\mathrm{pH}$ of the solution to 8 with $20 \%$ Sodium hydroxide aqueous solution. Then add the powder of camellia oleifera cake at the speed of $10 \sim$ 20 grams $/$ min. the $\mathrm{pH}$ should be kept stable during the process of 20-60minutes' high speed stirring. Finally, when the reaction is completed, we should cool down the container and take out the product. Then we get the camellia oleifera cake adhesive.

Other reagents such as: $\mathrm{NaOH}, \mathrm{HCl}, \mathrm{Na} 2 \mathrm{CO} 3$ : analytical pure, Sinopharm Chemical Reagent Co., Ltd

Poplar veneer:fast-growing poplar in Northeast, The moisture content is $8 \sim 11 \%, \quad$ size: $300 \mathrm{~mm} \times 300 \mathrm{~mm} \times 1.6 \mathrm{~mm}$, Wen an, He bei。

\subsection{Experimental instruments}

Varian 300 superconducting nuclear magnetic resonance instrument: Varian Technology Co., Ltd;

Tensor27 Fourier transform infrared spectrometer: Bruker company, Germany;

Dsc-60 / 60A differential scanning calorimeter: Shimadzu company, Japan;

PHS-3B multifunctional $\mathrm{pH}$ meter: Shanghai Precision Scientific Instrument Co., Ltd;

Jj-1 precision booster electric mixer: Jintan Kejian Instrument Co., Ltd;

3856 experimental hot press: American Carver company; Wdw50d microcomputer controlled electronic universal testing machine: Jinan Shijin Group Co., Ltd.

\section{Methods for experiment}

\subsection{Preparation for PF-Camellia oleifera cake}

Add an appropriate amount of PF - Camellia oleifera cake adhesive into plastic containers. then add30 percent $\mathrm{Na} 2 \mathrm{CO} 3$ aqueous solution.(solid $\mathrm{Na} 2 \mathrm{CO} 3$ that accounts for the whole solution ) stir the solution until it even. Then stir it with glass rod evenly under high shear. In this way we get well-prepared adhesive.

\subsection{Gel time test}

Take 4 grams prepared adhesive into a test tube.(be cautious not to make the sample adhere to the tube wall) then insert a piece of thin wire into the tube. When the temperature of methyl silicone oil in the short neck flask reaches the required temperature $\left(130^{\circ} \mathrm{C}, 140{ }^{\circ} \mathrm{C}\right)$, then put the test tube with iron wire into it. Then instantly start the stop watch. During this period, the temperature of the methyl silicone oil should be kept unchanged. The liquid surface should be lower than the surface of methyl silicone oil for $20 \mathrm{~mm}$. adhesive turns solid with constant stirring. Until the stir rod can't be lifted up suddenly, stop the stopwatch and set down curing time. Do the parallel experiment 3 times for each sample. the difference in parallel experiments shouldn't exceed 5 seconds. Then get the average of 3 valid results. The result is accurate to one second.

\subsection{Preparation of plywood}

Apply the Camellia oleifera cake(content of $\mathrm{Na} 2 \mathrm{CO} 3$ accounts for $2 \%$ of the total quality.) to the poplar veneer. Then prepare 3-layers plywood according to the conditions in the table1.

Tab.1 Factors and levels of the orthogonal experiment

\begin{tabular}{ccccc}
\hline Level & $\begin{array}{c}\text { Hot-press } \\
\text { temperature }\left({ }^{\circ} \mathrm{C}\right)\end{array}$ & $\begin{array}{c}\text { Hot- } \\
\text { press } \\
\text { time }\end{array}$ & $\begin{array}{c}\text { Glue } \\
\text { spread/single } \\
\text { side }\end{array}$ & $\begin{array}{c}\text { Hot- } \\
\text { press } \\
\text { pressure }\end{array}$ \\
\hline 1 & 110 & 2 & 120 & 0.9 \\
2 & 120 & 3.5 & 140 & 1.1 \\
3 & 130 & 5 & 160 & 1.3 \\
\hline
\end{tabular}

\subsection{Test for water resistant adhesive strength}

Use the standard test of class II panels in "GB / T 176574.15-1999 test method for physical and chemical properties of wood-based panels and veneered woodbased panels"

\section{Results and analysis}

\subsection{Optimization of hot pressing process parameters}

Orthogonal experimental design has many advantages such as: less times of experiments, representativeness. This method also can show the main factor among the complex factors and analyze rules that how each factor affects the index. Therefore, we take this method to carry out this experiment. Optimize the hot pressing process of PF- Camellia oleifera cake with the catalyst of $\mathrm{Na} 2 \mathrm{CO} 3$ through studying some impacts on the water resistant adhesive strength of conditions like hot pressing temperature, hot pressing time, unit pressure and gluing amount.

\subsubsection{Orthogonal test scheme}

According to the studied rules in literatures and process in factories, apply the orthogonal table with 3 levels and 4 factors L9 (34) in this experiment. The scheme is shown in figure 1

\subsection{2analysis of the results in orthogonal test}

(1) the influence on strength of water resistance of hot pressing temperature.

Hot pressing temperature have a direct influence on bonding performance of adhesive, hot pressing parameter 
and efficiency. It is an important factor to ensure the level of curing.

It can be concluded form the figure 1 that with the rising of temperature, bonding strength of the plywood rises up consistently. When the hot pressing temperature is $110^{\circ} \mathrm{C}$, the bonding strength of PF- Camellia oleifera cake is $0.34 \mathrm{MPa}$, which doesn't meet the required national standard of the class II plywood $(\geq 0.7 \mathrm{MPa})$. because the hot pressing temperature is so low that it doesn't reach the curing temperature $\left(128^{\circ} \mathrm{C}\right)$, the adhesive layer is loose and is not water resistant. With the rising of hot pressing temperature, The temperature gradient of the surface core layer of slab increases, which contributes to the heat conduction from surface to the core. And this increase can achieve complete curing of the adhesive between surface and core of the slab. Furthermore, this can also promote strengthening the bonding property on the surface between adhesive layer and veneer. The hot pressing temperature is higher, the permeability can be better, which makes the glue nail and intermolecular force easier to get. What's more, the rising temperature is helpful to polymerization of phenolic hydroxymethyl groups with active groups such as protein and tannin in PF-camellia oleifera cake gum and and deep crosslinking at the interface between polymer and binder. Therefore, when the hot pressing temperature rises to $130^{\circ} \mathrm{C}$, the bonding strength rises from less than $0.7 \mathrm{MPa}$ to $0.78 \mathrm{MPa}$. it means that bonding plywood is turned into qualified products meeting the requirements of class II plywood standard.

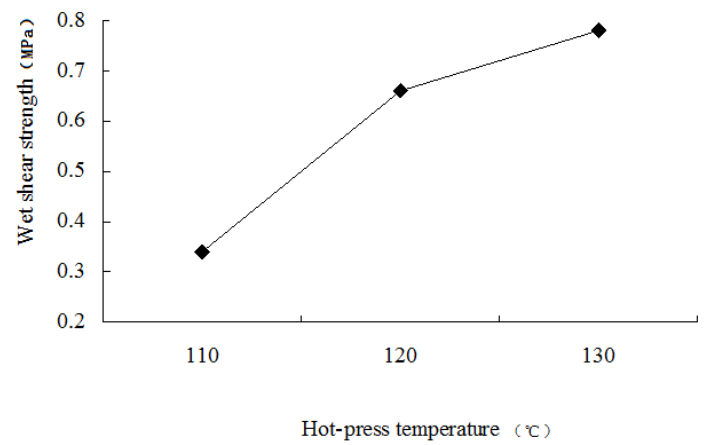

Fig. 1 Wet shear strength of plywood prepared by PF modified oil-tea based adhesive under different hot-press temperature Higher strength can be gotten if the hot pressing temperature continues rising up. However,

If the temperature is too high, it can cause excessive vapor pressure in the board, which can lead to bubbling and other quality defects during pressure relief. Besides, high temperature will degrade some chemical compositions in wood, so the bonding property will be impacted it. there will be deformation and discoloration in plywood. What's more, higher temperature causes more energy consumption. In this way, the cost of adhesive-making and plywood-bonding is higher.

(2) the effect on bonding strength and water resistance of hot pressing time.

It can be concluded from range analysis in table 2 and visual trend chart in table 4 that among 4 factors in hot pressing, the effect on bonding strength of hot pressing is the most notable. The time of hot pressing depends on growth rate of adhesive layer temperature, slab thickness, curing rate of adhesive layer and water removal rate. With the longer hot pressing time, bonding strength of adhesive increases suddenly at the beginning and then rises up slowly. When the hot pressing time is 2 minutes, the bonding strength is $0.29 \mathrm{MPa}$. When the hot pressing time is extended to $3.5 \mathrm{~min}$ and $5 \mathrm{~min}$ respectively, the corresponding bonding strength increases to $0.71 \mathrm{mpa}$ and $0.77 \mathrm{mpa}$ respectively.

Tab. 2 Results and range analysis of orthogonal experiment

\begin{tabular}{cccccc}
\hline NO. & $\begin{array}{c}\text { Hot-press } \\
\text { temperature }\end{array}$ & $\begin{array}{c}\text { Hot-press } \\
\text { time } \\
(\mathrm{min})\end{array}$ & $\begin{array}{c}\text { Glue spread/ } \\
\text { single side } \\
\left(\mathrm{g} / \mathrm{m}^{2}\right)\end{array}$ & $\begin{array}{c}\text { Hot-press } \\
\text { pressure } \\
(\mathrm{MPa})\end{array}$ & $\begin{array}{c}\text { Wet shear } \\
\text { strength } \\
(\mathrm{MPa})\end{array}$ \\
\hline 1 & 110 & 2 & 120 & 0.9 & 0.11 \\
2 & 110 & 3.5 & 140 & 1.1 & 0.54 \\
3 & 110 & 5 & 160 & 1.3 & 0.38 \\
4 & 120 & 2 & 140 & 1.3 & 0.41 \\
5 & 120 & 3.5 & 160 & 0.9 & 0.64 \\
6 & 120 & 5 & 120 & 1.1 & 0.93 \\
7 & 130 & 2 & 160 & 1.1 & 0.36 \\
8 & 130 & 3.5 & 120 & 1.3 & 0.95 \\
9 & 130 & 5 & 140 & 0.9 & 1.03 \\
Mean & 0.34 & 0.29 & 0.65 & 0.59 & \\
1 & & & & & \\
Mean & 0.66 & 0.71 & 0.67 & 0.61 & \\
2 & & & & & \\
Mean & 0.78 & 0.77 & 0.46 & 0.56 & \\
3 & 0.44 & 0.48 & 0.21 & 0.05 & \\
Range & 0.49 & & & \\
\hline
\end{tabular}

In PF - Camellia oleifera cake gum, PF component and polymer cross-linking with it play an important role in wet shear strength of adhesive. Because PF component has hydroxymethyl group with high reactivity, at specific curing temperature, the longer hot pressing time is, the more completely adhesive cures, which contributes to forming of water-resistant structure. The extension of hot pressing time will make the adhesive in the board have high curing rate, which can let the plywood free from bubbling. However, hot pressing time shouldn't be excessive. Otherwise, it leads to over curing of adhesive on the surface of board and degradation of wood cellulose macromolecules, which weakens bonding strength. According to the range analysis, the difference between the mean value 2 and the mean value 3 is very tiny, and both meet the requirements of class II board in the national standard. According to the comprehensive relation between hot pressing time and cost, the proper hot pressing time should be 3.5 minutes in this experiment.

(3) effect on wet shear strength of glue applied

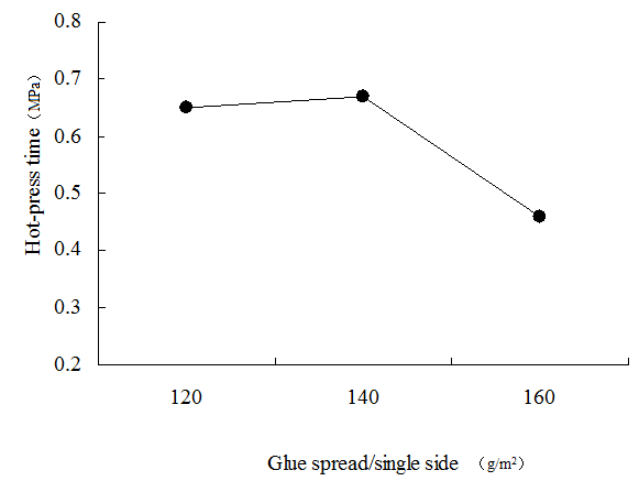

Fig. 2 Wet shear strength of plywood prepared by PF modified oil-tea based adhesive under different glue spread 
Figure2 shows effect on wet shear strength of glue applied. Proper amount of glue makes the adhesive layer thin and even. This lessens the applied adhesive to economize. What's more, it lessens stress concentration. So that it can improve the aging resistance of bonded joints.

It can be found from table- 2 and figure- 3 that with the increase of the amount of applied glue, bonding strength rises slowly then goes down suddenly. This is because with the increase of glue spread, the bonding surface between glue and veneer increases, too. Therefore, the combination between wood and adhesive is more compact and firm and the mechanical properties of plywood is enhanced. When glue spread goes up from $120 \mathrm{~g} / \mathrm{m} 2$ to $140 \mathrm{~g} / \mathrm{m} 2$ bonding strength turns from $0.65 \mathrm{MPa}$ to $0.67 \mathrm{MPa}$. the mean values are almost the same. It means that when the glue spread is $120 \sim 140$, it has little influences on bonding strength. When the amount rises to $160 \mathrm{~g} / \mathrm{m} 2$, bonding strength decreases on the contrary. This is because that with the constant increase of glue spread, the adhesive layers will be uneven and the thickness isn't same. There are great differences in properties among different parts of the board due to lack of adhesive. The property of the whole board will be lessened. Take all analysis into consideration, glue spread should be $120 \sim 140 \mathrm{~g} / \mathrm{m} 2$.

(4) the effect on wet shear strength of plywood hot pressing pressure

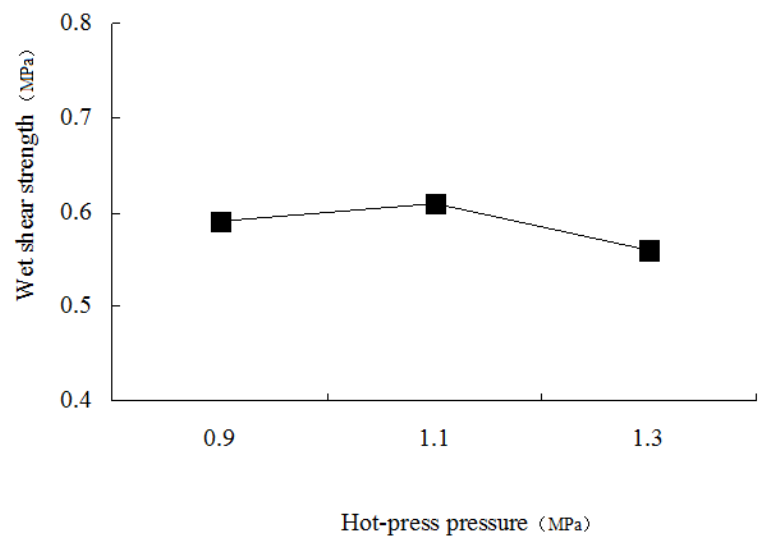

Fig. 3 Wet shear strength of plywood prepared by PF modified oil-tea based adhesive under hot-press pressure

It can be concluded from table2 and 3 that hot pressing pressure has the least impact on bonding strength. Figure 4 shows that when the pressure rises up from $0.9 \mathrm{MPa}$ to 1.1MPa. bonding strength rises up slowly. When the hot pressing pressure reaches $1.1 \mathrm{MPa}$, bonding strength reaches the maximum, $0.61 \mathrm{MPa}$. when the pressure rises to $1.3 \mathrm{MPa}$, bonding strength decreases. To make the board-adhesive-board layers combine with each other closely. We need to increase the pressure of slab during bonding. Then let some adhesive infiltrate into holes so that bonding quality will be good enough. Proper pressure compacts the slab tightly and accelerates the uniform diffusion of glue liquid and make the liquid penetrate into the wood, so that the adhesive can wet the surface of plywood better and reduce the gap of adhesive layer and increase the cohesion of glue layer molecules. Because of poor fluidity permeability of PF-camellia oleifera cake gum, higher hot pressing pressure is helpful to the improvement of flow ability and the amelioration of adhesive layer structure of adhesive.

Additionally, with some pressure, active groups in PFcamellia oleifera cake gum can react with hydroxyls on the surface of wood or generate firm glue nail in the holes inside the wood. So that bonding strength of adhesive is enhanced. However, when the pressure is beyond the proper value, it will cause higher consumption of energy during hot pressing and over-penetration of adhesive into the wood that lead to lack of adhesive in the adhesive layer. Finally bonding strength is lessened. Because of much fine powder of cake in the PF-camellia oleifera cake, only if the pressure is high enough while hot pressing, then the adhesive and wood can be compacted completely. Therefore, in this experiment, the proper hot pressing pressure is $1.1 \mathrm{MPa}$.

\subsection{3 working out the best hot pressing process of PF-camellia oleifera cake gum}

Given that properties meeting the national standard and the least cost are two premises, we have taken plenty of factors into consideration and we have analyzed hot pressing process obtained by orthogonal test to conclude better conditions of hot pressing of PF-camellia oleifera cake gum. The factors include hot pressing temperature, hot pressing time, glue spread, and hot pressing pressure. The hot pressing temperature is $130^{\circ} \mathrm{C}$, the hot pressing time is $0.7 \mathrm{~min} / \mathrm{mm}(42 \mathrm{~s} / \mathrm{mm})$, the gluing amount is $120 \mathrm{~g}$ $/ \mathrm{m} 2$, and the hot pressing pressure is $1.1 \mathrm{MPa}$. these conditions above are better ones we have obtained. Prepare the plywood under these conditions and then test bonding strength. We can clear that the wet shear strength of PF- camellia oleifera cake gum is $1.01 \mathrm{MPa}$. this value is far beyond $0.7 \mathrm{MPa}$, which is the minimum strength value of class II plate required in national standard. But in this process, hot pressing temperature is significantly higher than urea formaldehyde resin adhesive. (110 $115^{\circ} \mathrm{C}$ ) Remaining other parameters unchanged, we decrease hot pressing temperature and further optimize this process to adapt to the production conditions in factories. Values in tab.3 are wet shear strength of plywood under different hot-press temperatures of plywood. In this table, we can clear that decrease of hotpress temperature can lead to decrease of wet shear strength, but when the temperature reaches $120^{\circ} \mathrm{C}$, wet shear strength of prepared plywood is $0.79 \mathrm{MPa}$. This value still meets the required wet shear strength of class II plywood in national standard. Therefore, given that hotpress temperature in the second process is similar to that of urea formaldehyde resin adhesive, we select this process to be the optimum hot pressing process of PFcamellia oleifera cake adhesive. Repeatedly examine the bonding strength, we conclude that the mean value of bonding strength is $0.79 \mathrm{MPa}$. The coefficient of variation of each bonding strength is less than $2 \%$,which means that the optimum hot-press process is highly stable and reliable. 
Tab. 3 Wet shear strength of plywood under different hot-press processes

\begin{tabular}{|c|c|c|c|c|c|}
\hline \multirow[b]{2}{*}{$\begin{array}{c}\text { proc } \\
\text { ess }\end{array}$} & \multicolumn{4}{|c|}{ Hot-process conditions } & \multirow[b]{2}{*}{$\begin{array}{c}\text { Wet } \\
\text { shear } \\
\text { strengt } \\
\text { h } \\
\text { (MP } \\
\text { a) }\end{array}$} \\
\hline & $\begin{array}{c}\text { Hot- } \\
\text { press } \\
\text { tempera } \\
\text { ture } \\
\left({ }^{\circ} \mathrm{C}\right)\end{array}$ & $\begin{array}{c}\text { Hot- } \\
\text { press } \\
\text { time } \\
(\mathrm{s} / \mathrm{m} \\
\mathrm{m})\end{array}$ & $\begin{array}{l}\text { Glue } \\
\text { spread } \\
(\mathrm{g} / \mathrm{m} \\
2)\end{array}$ & $\begin{array}{c}\text { Hot- } \\
\text { press } \\
\text { press } \\
\text { ure }\end{array}$ & \\
\hline 1 & 110 & 42 & 120 & 1.1 & 0.43 \\
\hline 2 & 120 & 42 & 120 & 1.1 & 0.79 \\
\hline 3 & 130 & 42 & 120 & 1.1 & 1.01 \\
\hline
\end{tabular}

\section{Discussion and conclusion}

(1) adding some $\mathrm{Na} 2 \mathrm{CO} 3$ can promote instant curing at low temperature while preparing PF- camellia oleifera cake adhesive. Compared with PF- camellia oleifera cake adhesive, the adhesive catalyzed by $\mathrm{Na} 2 \mathrm{CO} 3$ has higher

$\Delta_{H}$. this means that the latter adhesive performs curing reaction more violently and completely. When the dosage of $\mathrm{Na} 2 \mathrm{CO} 3$ is $2 \%$, it can accelerate quick curing effect on PF- camellia oleifera cake adhesive at its best.

(2) DSC analysis of the curing characteristics of the adhesive shows that protein, tannin and other active components in PF- camellia oleifera cake adhesive perform cross-linking reaction with $\mathrm{PF}$ resin structural unit while curing. Water resistant structural system in PFcamellia oleifera cake adhesive is built by polycondensation reaction performed by structural components of PF resin and active components such as protein and tannin and chemical reaction of each active structure in PF resin and Camellia oleifera cake.

(3) optimize hot-press process of PF- camellia oleifera cake adhesive catalyzed by $\mathrm{Na} 2 \mathrm{CO} 3$ with orthogonal experimental design method. Then it can be concluded that among the four parameters of hot-press process, the time of hot pressing affects the result the most significantly. On the contrary, hot-press pressure has a least influence on the result. Increasing the hot-press temperature can raise wet shear strength of plywood; the optimal hot-press process is as follows : Hot-press temperature is $120^{\circ} \mathrm{C}$, hot-press time is $0.7 \mathrm{~min} / \mathrm{mm} \mathrm{(42}$ $\mathrm{s} / \mathrm{mm}$ ) 、 glue spread is $120 \mathrm{~g} / \mathrm{m} 2$, hot-press pressure is $1.1 \mathrm{MPa}$; under these conditions, average wet shear strength of prepared plywood is $0.79 \mathrm{MPa}$, which meets the national required standard for class II plate in GB / T 9846.3-2004.

\section{Acknowledgements}

This work was financially supported by the Special funds for construction of innovative provinces in Hunan Province (high-tech industry science and technology innovation leading program, No.2020GK4094), National Key Research and Development Program for International Science and Technology Cooperation Projects (No.2017YFE9135300).

\section{References}

1. A. X. Luo, Y. H. Liu. Study on water resistance of soybean-based wood adhesives. Agricultural Products Processing, 2006, 6: 15 18;

2. J. Y. Gu. Adhesives and Coatings. Beijing: China Forestry Press, 1999, 49 87;

3. D. B. Fan, J. Z. Li, Z. L. Lu. Thermal behavior and gluing plywood properties of low molar ratio ureaformaldehyde resins with different curing agents. China Adhesives, 2006, 15(12): 1 5;

4. C. M. Ding, Q. P. Song, L. L. Wang. Development of orthogonal corn starch adhesives. Chemistry and Adhesion, 2002(6):265 266;

5. Experimental Design Group, Department of Mathematics, Peking University. Orthogonal test method. Beijing: Science Popularization Press, 1981, $21 \sim 43$;

6. D. B. Fan, T. F. Qin, F. X. Chu. A New Interior Plywood Adhesive Based on Oil-Tea Cake. Advanced Materials Research, 2011, 194-196 (4): $2183 \sim 2186$;

7. H. Lei, A. Pizzi, P. Navarrete, et al. Gluten Protein Adhesives for Wood Panels. Journal of Adhesion Science and Technology, 2010, 24 (15): 1583 1596;

8. G. A. Amaral-Labat, A. Pizzi, A. R. Gonçalves, et al. Environment-friendly Soy Flour-based Resins without Formaldehyde. Journal of Applied Polymer Science, 2008, 108 (1): 624 632;

9. D. B. Fan, J. Zh. Li, J. M. Chang, et al. Chemical Structure and Curing Behavior of Phenol-UreaFormaldehyde Cocondensed Resins of High Urea Content. Journal of Adhesion Science and Technology, 2009, 23 (9): $1787 \sim 1797$;

10. G. VÁZQUEZ, F. LÓPEZ-SUEVOS, A. VILLARGAREA, et al. 13C-NMR Analysis of Phenol-ureaformaldehyde Prepolymers and Phenol-ureaformaldehyde-tannin Adhesives. Journal of Adhesion Science and Technology, 2004, 18 (13): $1529 \sim 1543$. 